UDC 7.036:82.02:1/14

Mane KHACHIBABYAN

\title{
THE CONCEPT OF TIME IN THE WORKS OF MODERNISTS
}

\begin{abstract}
Time is an important matter of study in science, religion, philosophy, art and literature. The issues that interest scholars and theorists are reflected in the art and literature as well, since those are the embodiments of society, its mind, life and issues. Historical traditions, economic, social and political features have huge impact on the perceptions of concepts and theories. This article aims to identify the relationship between the concept of time and art/literature. Through analysis of the works of modernist artists and authors the article will showcase the representations of the concept of time in the works of Charles Baudelaire, Salvador Dali, Walter Benjamin and Henri Bergson.
\end{abstract}

Keywords: time, modernism, science, philosophy, literature, art, Charles Baudelaire, Salvador Dali, Walter Benjamin and Henri Bergson.

Time has been a significant subject of study in science, philosophy and religion. Art and culture are the reflections of the society, its mind and life. Thus, the issues that interest scholars, scientists and philosophers are reflected in art and literature as well. The perceptions of different concepts tend to change based on historical traditions, economic, social and political life. This essay will discuss the concept of time by referring to the works of authors and artists of modernism period, such as: Henri Bergson, Charles Baudelaire, Salvador Dali and Walter Benjamin.

The expressions and symbols of evaluating the concept of time differ from writer to writer or artist to artist. Each author has his/her own perspective and style of presenting the ideas. French philosopher Henri Bergson, came up with the theory of "duree" or "duration" which is about time and consciousness. Bergson believed that the tradi- tions of scientific experience are irreconcilable with lived practice. Bergson got to be mindful that it is impossible to measure the moment and once one tries to do that it will already be gone. Duration, according to him, is the stream of time. Despite the fact that we can separate this continuous stream into sections of time or "states of consciousness" the information that we have is only derived from "concrete time" or the original source of duration. Hence, length of time can't be known in the typical feeling of "knowing." It requires a specific sort of access or plunge into the self in order for the mind to experience this flux in its creativity and originality (Bergson, 2001). Duration in other words can only be seen through small fragments and can never make a complete image. To grasp duration one can only rely on intuition. This theory of duration was a product of need to understand the reality and change at that time and as a whole. 
Bergson's philosophy presents the scientific explanations of time. It is interesting to explore how the concept of time was seen by not only scientists and scholars but poets of the same time period as well. Charles Baudelaire (1821 - 1867), a French poet, had his huge input in forming the modernist literature. $\mathrm{He}$ is most famous for his work "Les Fleurs du mal" (The Flowers of Evil). This collection of poems expresses the change in the nature of beauty the modern and industrialized world. Baudelaire is special for his outstanding style of prose-poetry writing and spreading the duty of art, which is according to him to capture human experience. In his prosepoem “Be Drunk” (Paris Spleen 1864), Baudelaire discusses time as a pressure that does not let people fully enjoy their lives: "You have to be always drunk. That's all there is to it - it's the only way. So as not to feel the horrible burden of time that breaks your back and bends you to the earth, you have to be continually drunk." Another poem from "The Flowers of Evil" - "The Clock" discusses time as well. In this poem, Baudelaire presents time as an evil and treat that reminds and creates our sorrows:

Clock! Sinister god, terrifying, impassive, Whose finger threatens us and says: "Remember!

The quivering Sorrows will soon be shot Into your fearful heart, as into a target;

"Nebulous pleasure will flee toward the horizon

Like an actress who disappears into the wings;

Every instant devours a piece of the pleasure Granted to every man for his entire season."
"Three thousand six hundred times an hour,

\section{Second}

Whispers: Remember! — Immediately

With his insect voice, now says: I am the Past And I have sucked out your life with my filthy trunk!"

Baudelaire presents time as something superior to human beings. He sees no way of living without it or without the idea of pressure and rush. The only way to live with it is as he puts in the poem "Be Drunk" is to be actually drunk.

"Remember! Souviens-toi, spendthrift! Esto memor!

(My metal throat can speak all languages) Minutes, blithesome mortal, are bits of ore That you must not release without extracting the gold!"

"Remember, Time is a greedy player Who wins without cheating, every round! It's the law.

The daylight wanes; the night deepens; remember!

The abyss thirsts always; the water-clock runs low."

"Soon will sound the hour when divine Chance,

When august Virtue, your still virgin wife, When even Repentance (the very last of inns!), When all will say: Die, old coward! It is too late!"

Time and duration are superior to men. Going back to Bergson we can state that humans are never capable of fully grasping the time, but just getting to know it through fragments. Thus, they feel inferior to it as writes 
Baudelaire. Time can be seen as something unknown and unrecognizable. Time changes individuals' whole life, yet never allows them to experience the feeling of fully knowing what time really is.

Time or the "clock" symbol for it helps people organize their life. Time is also revealed in the concept of human age. But is that all? The concept of time has had a significant influence on visual arts. Artists depict different symbols for time in order to present and reflect it as an important issue in human existence. The perspectives of artists are different; hence the expressions of time differ as well.

Salvador Dali, a Spanish surrealist painter is famous for his unusual, weird and enig- matic subject matter and style. His most famous art work is considered to be The Persistence of Memory (1931) or just "Clocks" as many call it. The painting is a masterpiece of Surrealist art that conveys multiple emotions and ideas. The concept of time is portrayed with the symbols of melted clocks. What does the painting really say about time and Dali's perception of time? The painting is open to representations, however if one pays close attention the details it might actually give out cues on Dali's perceptions and idea of time. In the painting, four clocks are on display in an empty desert, bent out of shape which conveys the impression of ongoing action of melting. Dali defined art as "hand-painted” dream photographs" (Bradbury, 1999).

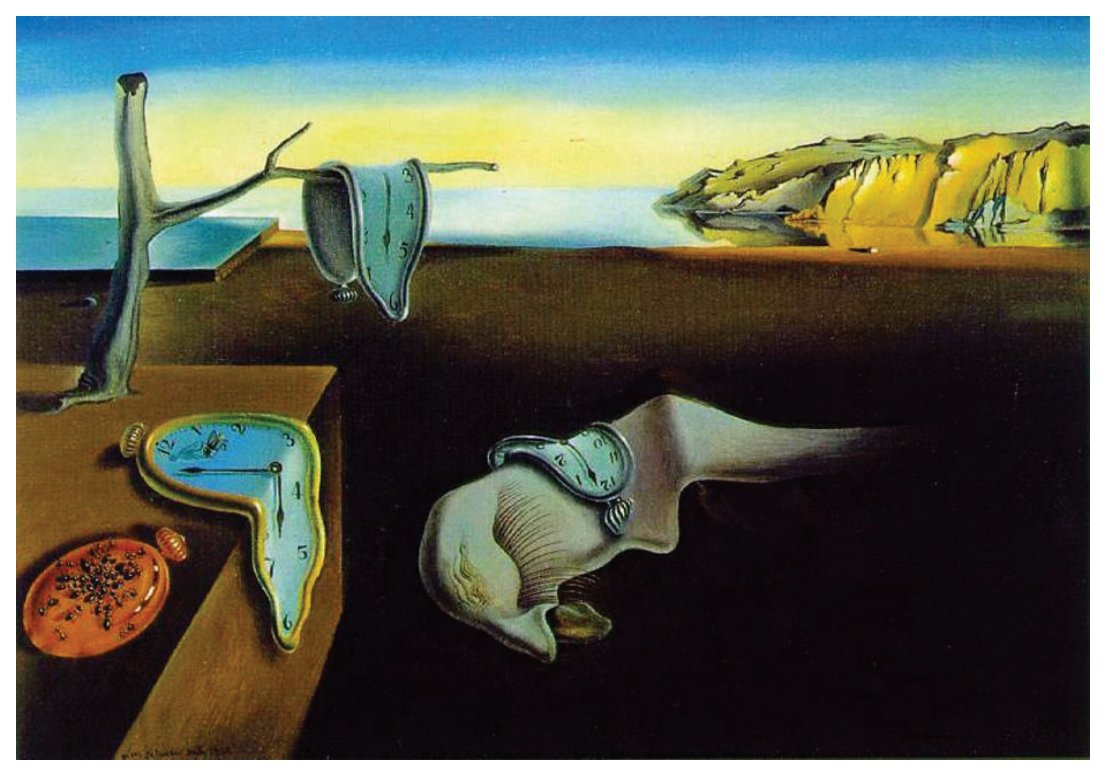

The photographic quality of the painting and the fact that there are no humans in it make it even more complex. There are many diverse ways to interpret Persistence of Memory. One way to look at it is a depiction of a dream state where the melting clocks symbolize the time experienced while dreaming. Human beings are some- how able to keep track of time during the day, but what happens with time when we are asleep is a matter of questions. Dali suggests with his painting that the distorted and melting clocks do not have power during the dream state or in the dream world. The painting illustrates how delusional and irrelevant the concept of time is during the 
dream state. Hence, it can also symbolize the inferiority of it versus human beings.

In 1930s Albert Einstein's Theory of Relativity brought a huge revolutionary idea. Einstein's theory proposed a whole new concept of time which characterized time as something complex and relative, not easy to track and not fixed. His theory undermined the ability of simple clocks or pocket watches to keep track of time (Einstein, 1916). In the painting, Persistence of Memory, Dali's melting clocks can be assimilated with Einstein's idea of time. The melting clocks symbolize the world, technology and its progressed society losing power against time. Alike, Einstein's theory, Dali might want to state with his painting that simple machines like clocks and pocket watches are too primitive to grasp time.

The concept of time has been of much importance for different scholars, scientists and artist all the time. We see that each and every of them has his/her own way of perceiving, expressing and presenting the ideas. Various factors effect on artists' viewpoints and ways of expression. Time period, socio-economic conditions, psychological state and even political life are features influencing this or that idea and theory. From the works of three modernists Henri Bergson, Salvador Dali and Charles Baudelaire discussed, one can see the connection of common ideas. One cannot be sure whether the interconnectedness is because of the fact that artists were influenced by modernism, but one can guess that the modernism as time period had significant impact on the artists' and theorists' perceptions. Three of them are absolutely different individuals from different backgrounds, however they happen to perceive and discuss the concept of time as something that can hardly be grasped by human beings. Time was seen by them as superior to people, as well as the simple technology created by them, because of its complex, not fixed, uncertain and partially unknown nature.

\section{REFERENCES}

Baudelaire, C. (1970). Paris Spleen. New Directions; F First Edition edition.

Baudelaire, C. (2008). The Flowers of Evil. Oxford University Press.

Bergson, H. (2001). Time and Free Will: An Essay on the Immediate Data of Consciousness. Dover Publications.

Bradbury, K. (1999). Essential Dali. Dempsey Parr.

Einstein, A. (1916). Rleativity: The Special and General Theory. Translation 1920. New York: H. Holt and Company. 